\title{
Ability, individual development and optimal selection decisions
}
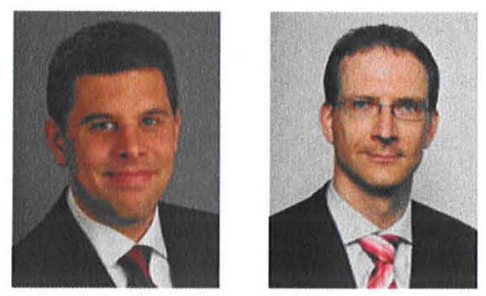

Gerald Eisenkopf • Christian Lukas

\begin{abstract}
The paper analyzes different selection policies in education and business. We show that incorrect self-perceptions combined with imperfect performance measurement may cause significant welfare losses in selective educational systems, in particular if selection starts too early. Of course, these welfare losses can be mitigated by an investment in better ability assessment. However, an affirmative action policy could scrve the same purpose as such an investment. We apply our analysis also to diversity management in firms. Based on positive discrimination we establish an efficiency argument for diversity management.
\end{abstract}

Keywords: Education $\cdot$ Selection · Affirmative action

JEL Classification: I28 $\cdot \mathrm{J} 15$

Dr. G. Eisenkopf $(\bowtie)$

University of Konstanz, Department of Economics and Thurgau Institute of Economics, Box 131, 78457 Konstanz, Germany

e-mail: Gerald.Eisenkopf@uni-konstanz.de

Prof. Dr. C. Lukas

University of Konstanz, Department of Economics, Box 144, 78457 Konstanz, Germany

e-mail: Christian.Lukas@uni-konstanz.de 


\section{Introduction}

Schooling and training shape the individual development of students or young professionals. However, the implication of cognitive and non-cognitive learning processes on educational policies has not been discussed in the theoretical literature. Most theoretical models on the economics of education endow students with a time-invariant productivity parameter: Ability (e.g. De Fraja and Landeras 2006, or in a different specification, Lazcar 2001). In these models externalities in educational production, e.g., peer effects, are typically decisive whether or not an ability-based selection of learning groups (classes or schools) is efficient (see for an early discussion, Arnott and Rowse 1987). ${ }^{1}$

Our paper approaches the selection problem from a different perspective. We model an education process in which education shapes cognitive skills (ability) and non-cognitive characteristics (attitude) and subsequently the performance of a student over time. Our model captures key aspects of the relationship between self-perception, attitude and ability as they are described in psychological textbooks (e.g. Sternberg and Williams 2002 or Wild et al. 2001). The setup is in line with analytical contributions like Compte and Postlewaite (2004) in which self-perception is not identical with ability. ${ }^{2}$ Selection according to ability would be efficient only if ability alone was perfectly observable. However, attitude as a further individual characteristic distorts the selection process.

Attitude represents a variable that is both difficult to observe and difficult to manipulate. This argument is motivated by psychological research about the importance of a student's self-perception for academic outcome. The psychological literature (e.g. Heckhausen and Gollwitzer 1987; Köller 2004; or Achtziger and Gollwitzer 2006) has a strong research focus on the importance of a person's self-perception on her performance, as the selfperception critically influences the general attitude of a student towards education. ${ }^{3}$ Family background, ethnicity or socio-economic status have an impact on the educational attitude and performance over time, as a detailed survey by Lee and Burkam (2002) shows. Blanden et al. (2007) provide evidence from Britain that the growing imbalance in access to higher education by family background is partly driving the decline in intergenerational mobility in the UK. They find that the intergenerational transmission of noncognitive variables (like our variable attitude) but not cognitive ability is important for this development. genetically transmitted intelligence is unlikely to be a substantive drive. Therefore most empirical studies indicate that early selection in schools increases inequalities in outcomes (Hanushek and Woessmann 2006) and diminishes vertical mobility via an educational career in many societies (Dustmann 2004; Meghir and Palme 2005; Bauer and Riphahn 2006; Brunello and Checchi 2007).

Our paper shows that these observations also have an important meaning for the efficiency of selection in education. The non-cognitive variable attitude in our model is a psychological state rather than a trait, as it changes over time. Even though attitude correlates positively with ability, a wrong timing can lead to inefficiency. The correlation increases over time, as the attitude adapts towards the actual ability. ${ }^{4}$ Consequently, we find that later selection is optimal. A large literature tries to identify if selection in education is efficient (Hanushek and Woessmann 2006; Manning and Pischke 2006; Waldinger 2007; or Eisenkopf 2009). However the question is not if selection is optimal but when. Selection after grade 4 may be questionable, but we are not aware of any academic paper 
which identifies uniform post-secondary education as an optimal solution. At this time selection is widely observable and arguably efficient (see Epple et al. 2003).

Our approach to education is broader than Judson's (1998). In Judson (1998) education improves skills and informs about ability, but it does not shape ability. Furthermore, there is no systematic disadvantage for students in Judson (1998) if ability is poorly observable. Brunello et al. (2004) also argue that imperfect observation of ability in younger years implies that the optimal selection date is rather late. They investigate how this delay affects the benefits from specialization into different vocations.

A discrimination policy based on the observable characteristic can support the identification of the high-ability students. Our results show that affirmative action can improve efficiency if it is carried out early. This argument goes hand in hand with the theoretical analysis by $\mathrm{Fu}$ (2006) who identifies affirmative action as a tool to provide similar starting positions for applicants. Prospective students then compete on the same level which induces higher incentives. In contrast to $\mathrm{Fu}(2006)$ though, our paper follows to a greater extent the theoretical approaches of Phelps (1972); Arrow (1973); Lundberg and Startz (1983), and, more recently, Furstenberg (2007) in which the principal's objective function is maximized when (statistical) discrimination is allowed. Therefore, we contribute to the surprisingly small theoretical literature on the efficiency aspects of discrimination in education (see Holzer and Neumark 2000). Affirmative action policies are an example of positive discrimination and education is the most prominent and controversial example for affirmative action. Our paper takes into account that many countries observe a great inequality in educational opportunities without the benefit of a high level of overall education (e.g. the USA, UK, Germany, or among the emerging economies Brazil and South Africa). Our explanation is that (self-)selection starts too early in these countries, so that 'raw' talent cannot be identified. In this context, affirmative action policies can improve efficiency and reduce inequality at the same time.

However, our argument extends to any organization that recruits, trains and promotes its staff on the criterion of skill. Positive discrimination in recruitment decisions by commercial firms presents an application of our results to business administration issues. To evaluate applicants early in their professional career, firms could justifiably apply less strict standards for applicants with a disadvantageous background if the latter is associated with lower ability assessments. For example, enrollees for vocational training who graduated from less reputable schools or employers may have more potential than those from better schools.

The results of our analysis can be summarized as follows:

- Early selection can be harmful as the wrong kind of student passes the selection threshold.

- As a consequence, the optimal selection date depends on the importance of attitude for observed performance and its ex ante correlation with actual ability.

- Observable, non-manipulable measures like gender or ethnicity that correlate positively with attitude can be used to improve the selection process. Hence the use of these measures can be linked to affirmative action policies.

- These observable measures could substitute investments in improving ability assessments.

- The application of affirmative action policy allows for earlier selection. 
The paper is structured as follows. The following section describes the framework for our analysis and elaborates on arguments about an optimal selection date. Section 3 discusses policy implications. In particular it focuses on the use of affirmative action as a selection instrument. In particular, we provide an efficiency argument why organizations practice 'diversity management'. The last section discusses the robustness of the results and concludes.

\section{The model}

In this section we describe the framework in which we derive our arguments in favor of later selection in schools and the use of affirmative action for that purpose. Consider an economy with a large population of students and a fixed schooling time $T$, stretching from 0 to 1 . For simplicity, assume there are just two schools in the economy. Let one-half of the students be enrolled in each of the two schools. Schooling starts with comprehensive education, i.e. all schools have the same educational productivity, $S_{1}=c$. At any time $t \in[0,1]$ during the fixed schooling time the government can change the productivity of the schools. One school is specifically designed to fit the needs of high ability students and the other one for those of low ability students, $S_{2}=\{\beta, \gamma\}$. Learning progress per student and year is assumed to be highest in the high-ability school (HAS) and lowest in the low-ability school (LAS). Stated differently, schools show different "productivities" in teaching students. To allow for the efficiency of selecting students in different school types we assume the learning progress in the comprehensive school (CS) ranks between those of HAS and LAS, $1 \leq \beta<\mathrm{c}<\gamma$, and is lower than the average of the two,

$$
c \leq \frac{\beta+\gamma}{2}
$$

In this paper, efficiency follows from total value maximization of student ability. The value maximizing selection decision is Pareto efficient.

For simplicity, commuting costs are zero, so students can easily be reassigned to other schools at the time of selection.

Each student has a certain attitude $A$ towards education which reflects his actual ability $a$. For some students attitude and actual ability coincide - the ex ante probability is $p-$, while for others they do not. On average, however, the attitude to learning and the actual ability do not differ. In other words, the average student's perception of his ability is correct. Formally, ability and attitude have a bivariate normal distribution $(a, A) \sim$ $B N\left(\mu, \mu, \sigma^{2}, \sigma^{2}\right)$, and marginal distributions $a \sim N\left(\mu, \sigma^{2}\right), A \sim N\left(\mu, \sigma^{2}\right)$.

During schooling, students accumulate knowledge and skills which add to their abilities. How much they learn, i.e. the learning progress, depends on the school type and the length of schooling in the particular type. In period 2, learning also depends on ability because school types in period 2 are tailored to the specific cohorts after selection. ${ }^{5}$ Ability increases as follows in period $t=(1,2):^{6}$

$$
\begin{aligned}
& \mathrm{a}_{1}=\mathrm{a}+\mathrm{t} \times \mathrm{S}_{1} \\
& \mathrm{a}_{2}=\mathrm{a}_{1}+(1-\mathrm{t}) \mathrm{S}_{2} \times \mathrm{a}_{1}
\end{aligned}
$$


Ability and school productivity are complementary inputs; therefore it is sensible to assign high (low) ability students to the high (low) ability school. Clearly, if the social planner was able to identify students' ability correctly at the beginning, selection should take place as early as possible to maximize ability gains of students. Equations (1) and (3) imply this result.

Lemma 1 If individual ex-ante ability is observable then selection at $t=0$ maximizes ex-post ability.

A student's performance $\Pi(\mathrm{a}, \mathrm{A})$ depends on both ability and attitude,

$$
\Pi(a, A)=a+\alpha A,
$$

where $\alpha, 0 \leq \alpha \leq 1$ measures the impact of attitude on student performance. (Here and especially for purposes of statistical inference the deterministic impact of learning is omitted. ${ }^{7}$ ) Given the distributional assumption for ability and attitude, student performance has a normal distribution ${ }^{8}$ with mean $E(\Pi)=(E(a)+\alpha E(A))$ and variance $\operatorname{Var}(\Pi)=$ $\sigma^{2}\left[1+2 \alpha \rho+\alpha^{2}\right]$.

Performance measurement is subject to noise so that observed or measured student performance $\pi$ obtains as

$$
\pi(a, A)=\Pi(a, A)+\varepsilon=a+\alpha A+\varepsilon, \quad \varepsilon \sim N\left(0, \sigma_{\pi}^{2}\right) .
$$

We assume that the impact of attitude on performance decreases over time. Students receive frequent feedback on their performance and, of course, this feedback aggregates effects of ability and attitude. Substantial aggregation leads to just a number (or letter) - the student's grade in a test; but even verbal evaluations along different dimensions are based on observable student performance and hence aggregate effects of ability and attitude. The "quality" of observed performance depends on the extent to which attitude influences performance. If that influence is weak, performance represents a good indicator of ability and can be used in the selection process. However, a strong influence generates less reliable indicators of ability. Especially at early points during schooling time, the influence of attitude can be very distorting in that respect. This approach implies a correlation between ability and attitude that increases over time. Such a correlation is documented in psychological textbooks (e.g. Sternberg and Williams 2002; or Wild et al. 2001) and confirmed by recent research (Hattie and Timperley 2007).

To model the impact of feedback on ability and performance, we suppose observed student performance amounts to

$$
\pi\left(a, A^{(n)}\right)=a+\alpha A^{(n)}+\varepsilon,
$$

where $A^{(n)}$ indicates the revised attitude after $n$ performance feedbacks. There are an exogenously given maximum number of performance measurements $N$ that are evenly distributed over schooling time $T$. Hence performance is measured every time unit $\tau=$ $T / N$, and the number of performance feedbacks $n=1 \ldots N$ unambiguously identifies a point during schooling time. The student's (innate) ability enters as a constant into performance measurement at any time. 
To determine the posterior mean of attitude note first that a student $i$ believes she has a correct estimate of her ability so that expected performance-adjusted for deterministic learning - for the first measurement obtains as $E\left(\pi_{i} \mid E\left(a_{i}\right)=A_{i}\right)=(1+\alpha) \mu_{i}$. One can show that an observation $\pi_{i}$ leads to the following posterior distribution ${ }^{9}$ of attitude for student $i$ :

$$
\begin{aligned}
A_{i} & \sim\left(\mu_{i}^{*}, \sigma_{i}^{*}\right), \quad \text { with } \\
\mu_{i}^{*} & =\frac{\sigma_{\pi}^{2} \mu_{i}+\sigma^{2} \frac{\pi_{i}}{1+\alpha}}{\sigma_{\pi}^{2}+\sigma^{2}} \\
\sigma_{i}^{2 *} & =\frac{\sigma_{\pi}^{2} \sigma^{2}}{\sigma_{\pi}^{2}+\sigma^{2}}
\end{aligned}
$$

The updating process as formalized in (6)-(7) repeats for every student after each performance measurement. Note that the attitude effect in measured performance will matter less for the posterior $\mu_{i}^{*}$ if $(1-\alpha)$ is low, i.e. if $\alpha$ is high. In other words, the information content of early observations becomes stronger the less influence attitude has on measured performance. Eventually, attitude will converge to actual ability. This convergence implies that measured performance becomes a better ability indicator over time. Formally, from the social planner's perspective, the linear combination of normally distributed ability and revised attitude in (4) will show increasing correlation between the two. And given the identical distributions of ability and attitude, the planner cannot infer more about one or the other and posteriors would again be equal; hence performance measurements and normal updates of the performance distribution in (4) are as informative as making inferences about ability and attitude separately, implying corresponding distributions. ${ }^{10}$

Selection into different school types at a given point in time has to rely on observed student performance. The social planner's intent is to sort high (low) ability students into school type HAS (LAS). Therefore, if a high (low) ability student is selected into school type HAS (LAS), we call it a correct selection. Given the increasing correlation between performance and ability, the latest possible selection date minimizes misallocation losses resulting from selecting high (low) ability students into school type HAS (LAS). At the same time, however, benefits from selection are minimized, too. To allow for a closed form solution that relates the optimal selection date to the two decisive parameters $p$ and $(1-\alpha)$, we simplify the model in two respects: First, students whose actual ability and attitude are initially equal to or larger than the mean ability $\mu$ are always correctly selected into school $h$; if they are both lower, students are correctly selected into school $l$. This correct selection applies for a fraction $p$ of the student population. (Actually, selecting students into different schools represents the outcome of an optimization stage. Given our assumptions, students with high ability and attitude, or low ability and attitude, respectively, would indeed be optimally selected in school $\gamma($ or $\beta)$ ). Setting a performance threshold $\tilde{\pi}_{\mathrm{t}}$ to qualify for school $\gamma$ at selection date $t=n \tau$ implies an ability threshold $\tilde{a}^{(t)}$ which takes previous performance observations into account.

The quality of selection is given by the share of high (low) ability students into school type HAS (LAS). We represent this quality with the likelihood that the observation of a performance beyond the threshold level is associated with high ability, and observation of 
lower than threshold performance results from low ability. To save on notation we define selection quality $q_{t}$ at time $t$ as

$$
q_{t}=(1-\alpha)+\alpha t
$$

Depending on the influence $\alpha$ of attitude on observed performance, it may take some time until performance becomes a reliable ability indicator. Associated with that is that early observations do not possess much value. At $t=0, q_{t}=(1-\alpha)$. With $\alpha$ increasing, an arbitrary level of selection quality $\bar{q}_{t}$ is reached later in schooling time if $\alpha$ increases. ${ }^{11,12}$ Towards the end of schooling, student ability and attitude are highly correlated. Then, even a continually strong influence of attitude on performance could not harm selection quality. Hence selection quality approaches its best level-implying no single wrong selection decision - at the end of schooling; at $t=1, q_{t}=1$. As a simplification, the mean ability of students having an actual ability higher (lower) than the implied threshold ability is assumed constant over time and denoted $h(l)$.

A note on the treatment of peer effects seems appropriate here. School productivity in school type HAS is higher than in type LAS, $\gamma>\beta$. Given that school type HAS (LAS) is designed for students with ability above (below) the threshold level, peer effects provide a possible explanation for this inequality. Of course, these effects (should) depend on peer quality, i.e., the quality of selection and the accumulated ability of peers up to the selection date. Doing so in our model would require additional analytical burden without changing results qualitatively. Section 4 discusses our approach in more detail.

A social planner's objective is the maximization of expected ability gains. ${ }^{13}$ Ability in this context may represent true labor market productivity while attitude is basically a systematic distortion in the measurement of labor market productivity. Selection is assumed to occur only once during an educational career. The social planner trades-off selection gains against its costs. Gains consist of additional ability accumulations made possible by correctly selecting high- and low-ability students into their corresponding school types. Costs of wrong selection decisions comprise foregone ability accumulation and possibly psychic costs for students if they feel the school does not fit their needs. Gains from selection steadily decrease over time because a later selection point leaves less time to learn in the specific school type, HAS or LAS. Unfortunately, costs of selection are highest at the beginning, too, and steadily decrease over time. Given that both gains and costs of selection decrease over time there has to be an optimal selection point during schooling.

In our model, ability gains for each student amount to $t c+(1-t) S_{2}(a+t c)$. A total surplus of

$$
T S(t)=t c+(1-t) \times\left\{\begin{array}{l}
{[t c(\gamma+\beta)]+p \times(\gamma h+\beta l)} \\
+(1-p) \times q_{t} \times(\gamma h+\beta l) \\
+(1-p) \times\left(1-q_{t}\right) \times(\beta h+\gamma l)
\end{array}\right\}
$$

obtains for the student population. ${ }^{14}$ The first term in (9) describes thse surplus $t c$ from comprehensive schooling for a period of $t$ for the entire population; the term in brackets represents the selection gains (or losses) accruing for a period $(1-t)$. The first line in brackets contains the surplus in selective schooling resulting from ability gains in comprehensive 
schooling for the entire population, $[t c(\gamma+\beta)]$, and the surplus from selective schooling for students with a match of ability and initial attitude the sense of (2), $p \times(\gamma h+\beta l)$. For students with no such match, the corresponding selection gains accruing to ability at the selection date amount to $(1-p) \times q_{t} \times(\gamma h+\beta l)$ if correctly selected into school type (line 2), and selection losses $(1-p) \times\left(1-q_{t}\right) \times(\beta h+\gamma l)$ if not (line 3$)$. Using (9), the social planner's decision problem can now be formalized: ${ }^{15}$

$$
\max _{t} T S(t)
$$

Proposition 1 characterizes the optimal selection date.

Proposition 1 (a) There exists a unique selection date $0 \leq t^{*}<1$, that maximizes total expected ability gains from schooling. If $c>h$ holds, then $0<t^{*}<1$, even if $\gamma \rightarrow \infty$. The optimal selection date $t^{*}$ is increasing in the importance of attitude for observed student performance, $\alpha$, and decreasing in the a priori correlation of ability and attitude, $p$, i.e. $\left(\partial t^{*} / \partial \alpha\right)>0$ and $\left(\partial t^{*} / \partial p\right)<0$. Furthermore,

(b) $\frac{\partial t^{*}}{\partial c} \leq 0 \Leftrightarrow \alpha(1-p) \geq \frac{(\gamma+\beta)(\gamma h+\beta l)}{(\gamma-\beta)(h-l)(\gamma+\beta-1)}$

(c) $\frac{\partial t^{*}}{\partial \gamma} \geq 0 \Leftrightarrow \alpha(1-p) \geq \frac{c[\beta(h-l)+c]}{(h-l)[\beta(h+l+2 c)-c]}$

(d) $\frac{\partial t^{*}}{\partial \beta} \leq 0 \Leftrightarrow \alpha(1-p) \geq \frac{c[\gamma(h-l)-c]}{(h-l)[\gamma(h+l+2 c)-c]}$

Proof. See Appendix.

According to proposition 1, the higher the influence of attitude on student performance, the later is the optimal selection date. However, a high correlation between ability and attitude may offset this effect and lead to an early selection.

One may suspect that the optimal selection also depends on school productivities. The higher the productivity during comprehensive schooling the lower will be the gains from (correct) selection. Also, a higher productivity in school type HAS should lead to earlier selection being optimal with the limit being the earliest possible date. Yet, as proposition 1(a) shows, even an arbitrarily large productivity $\gamma$ does not lead to optimality of $t^{*}=0$. The sufficient condition $c>h$ means that the marginal contribution of the comprehensive school to educational success is larger than the marginal contribution of the prospective students in the better school. Hence in case a sufficiently good comprehensive school exists, the social planner should never select students at the beginning of schooling; the option to wait and improve in selection quality becomes quite valuable then.

How does the optimal selection date change with changes in school productivities? Surprisingly, it may increase (or decrease) with a higher productivity in any of the three school types. Suppose a priori attitude strongly influences performance while correlation between ability and attitude is low. Increasing productivities in comprehensive school or the LAS-school leads to earlier selection being optimal while a higher productivity in the HAS-school delays the optimal selection date. If the opposite holds - attitude affects 
performance only slightly and correlation is high-the social planner finds it optimal to select later in reaction to an improving comprehensive school or LAS-school; a better HAS-school then allows for earlier selection. The important point being made is that while an increasing productivity in any particular school type is raising the value of learning in that school it also changes the option (value) of waiting to select. Hence an earlier or later selection date may be optimal.

In this paper, we assume selection takes place only once. A stepwise selection process could only lead to better results and therefore allow for an earlier selection. If students could be reassigned to schools later on it would give the social planner more leeway in his/her selection decision which facilitates the problem. However, more differentiation would not eliminate the basic trade-off of finding the optimal timing of selection steps.

\section{Selection based on additional characteristics}

Besides the optimal timing of selection (steps) there are various factors that can improve selection processes. One possible way to do so would be positive discrimination. Suppose an additional student characteristic could enter the selection decision. Let this observable, verifiable and non-manipulable variable be indicated by $X \in(\underline{X}, \bar{X})$; it could be, e.g., socio-economic status or ethnic background (as shown by Lee and Burkam 2002). Like ability $a$ and attitude $A$ this variable $X$ has the following characteristics: $X \sim\left(\mu, \sigma^{2}\right)$, but with $\operatorname{corr}(X, A)=\theta>0$ and $\operatorname{corr}(X, a)=0$. By assumption, that characteristic shows positive correlation with attitude but not with ability. The problem of the decision maker is to assign an optimal weight $w$ to this informative characteristic. This weight should maximize the correlation between the actual ability and the observable student performance with their respective weights. The weight of observed performance is standardized to one in this context. It is clear from the previous section that improved information about actual ability implies an earlier optimal selection date.

To make our point as clear as possible, we investigate the optimal weighting when schooling starts. At this time the influence of attitude on performance is very strong, i.e. attitude substantially distorts performance. The social planner cannot infer much about student ability from observing performance then. However, performance and the additional student characteristic allow for better inference, because the characteristic partially discloses student attitude. Therefore, observing high student performance and a low value for the characteristic suggests higher ability than observing high student performance and a high value for the characteristic. In other words, high student performance will be subject to downgrading if the characteristic shows a high value and vice versa. This negative weight is stronger if the correlation between attitude and characteristic increases and if the impact of attitude on performance becomes stronger.

Proposition 2 The optimal weight $w$ of an additional student characteristic positively correlated with attitude, but not with ability, is negative. It decreases in the correlation with attitude, $\theta$, and in the impact of attitude on student performance, $\alpha$.

Proof. See Appendix. 
Proposition 2 proves that promoting the chances of less privileged students to access school type HAS is valuable.

\section{Implications for schools and other organizations}

The optimal timing decision for selection has shown that early selection increases the benefits from selection for those who have been selected correctly, and late selection decreases the loss derived from wrong selection (proposition 1). Several policy implications follow from the analysis. Suppose a student's parental background has a strong impact on her educational performance but it is largely independent of her ability (as documented in Blanden et al. 2007). In this case, early selection is not just the root of inequality (as shown by Schuetz et al. 2008), it is also inefficient in the sense that aggregate gains from selection fall short of its costs for the social planner.

Hence, it is clear that early selection would be optimal only if the loss from wrong selection could be eliminated. A distinct measurement of ability and school performance reduces the loss. Therefore, intelligence tests or similar instruments improve the selection process. However, using signals about non-cognitive ability can improve selection in a similar way if the signal realization is independent from ability but has a strong impact on performance. An obvious implication would be to employ the signal "observable effort" for the selection decision. Among medium performers, more laid-back students are very likely to have higher ability on average than their hard-working fellow students. The argument readily extends into the business community and human resource management.

Proposition 2 suggests affirmative action as means to improve selective schooling because the selection mechanism discriminates against a subset of students. The negative weight, or affirmative action, results from the informativeness of the additional characteristic, e.g., gender or ethnic background. It represents an informative signal like any other one. Such a signal can substitute investments in better ability assessments. Therefore our results are comparable to a textbook analysis, as in Milgrom and Roberts (1992, p. 219 ff). However the literature has largely ignored this aspect in the analysis of selection and positive discrimination in educational organizations.

There is no doubt that the implementation of optimal affirmative action policies can run into difficulties. ${ }^{16}$ A possible shortcoming of basing selection decisions on certain group characteristics could be that those decisions may be easily overruled by additional information on, e.g., parental help for students when doing homework. If a student belonging to a disadvantaged group is known to receive substantial support for home assignments, she will be less likely to attend the better school type. The disadvantage of such additional information compared with group affiliation lies in its susceptibility to manipulation. If more (or less) proclaimed help increases the chance to attend the better school, parents may just deliver the "right" information. In addition to the problem of overturning decisions, finding the optimal weights is by no means trivial. Whatever the technical difficulties of finding an optimal weight may be, they do not eliminate our general point in favor of positive discrimination. For practical purposes, a quota for disadvantaged groups may serve as an approximation or substitute for a weighting formula. 
The application of results to current debates about affirmative action requires a caveat. These debates focus more on higher education or the job market while our analysis is based on discrimination at beginning of schooling. The use of informative signals allows for an earlier selection because it improves the identification of actual ability. Higher education starts rather late when observed performance correlates more strongly with actual ability. Affirmative action can better help in situations with a large mismatch between ability and observed performance which is less likely at the age of 18 when learning curves become less steep. Nevertheless, there may still be cases where affirmative action does help.

Access to higher education in Britain provides an interesting case study for our approach. Forsyth and Furlong (2003) find that performance in school is the most important factor for access to Higher Education in Britain. However, this performance increases with a student's socio-economic background characteristics. Moreover, well performing students are less likely to enroll in higher education if they come from a more disadvantaged background. A report by the Sutton Trust (2008) for Britain's National Council for Educational Excellence confirms these findings. The authors argue that, in Britain, the early years of schooling are critical for future status and income. Here, the key factor is enrolment into selective independent, i.e. not state-run, schools. Furthermore the report states that disadvantaged students are deterred from highly-selective institutions as they are not confident they will get in or, if they do, that they will fit in once there. Poorer students are less likely to get higher education support from their peer groups and families, which are influential in the decision-making process. Therefore, good students are more likely to see a decline in their performance, if they have more disadvantaged backgrounds.

Although schools are the most prominent examples for the benefits of a well-designed affirmative action policy, our argument also extends to commercial enterprises and indeed any organization that recruits and trains young people. Of course, we are aware of the differences between selection decisions in schools and commercial organizations. But given that school grades measure labor market productivity (if at all) only with noise, the two selection decisions share the uncertainty about students' or applicants' productivity. Selection in school decides on the school track (though some degree of permeability may be present), and a personnel decision defines the professional career. A high uncertainty about labor market productivity increases the value of the option to wait to decide on the career path in an organization. Trainee programs where young professionals are grouped can thus be considered as a sort of business counterpart to comprehensive schooling. Depending on applicants' characteristics or specific branch features trainee programs differ in length.

In some workplaces it may be efficient to put the more productive workers in one team and the rest in a second one. Entrepreneurship may serve as an example, where entrepreneurs seek to find the most productive partners for their venture. If productivity is not directly observable, differences in attitude could be misleading. Teams of firm founders may be inefficiently composed if observable productivity is systematically distorted (see Fabel 2005).

Diversity Management is the 'corporate response' to affirmative action (von Bergen et. al. 2002). It relates to corporate social responsibility when companies give particular support to women and underrepresented minorities (Gilbert et al. 1999). Our analysis shows that such a support even improves the recruitment of talent as long as social discrimination against minorities has a negative impact on the observed ability of an applicant. For 
example, a privileged applicant is more likely to obtain qualifications through enhanced self-confidence and social support, but a disadvantaged candidate will need more of her own skills to achieve the same result. According to our results the latter person is more likely to increase her productivity by learning on the job. Wright et al. (1995) report a positive relationship between affirmative action policies and stock-market performances. They argue that diversity management provides an advantage in the competition for talent. Kochan et al. (2003) argue that a rigorous evaluation of diversity management is still missing. To our best knowledge, this is still the case.

Diversity management makes less sense when recruiting for senior positions in a company. At this level the actual qualifications are much more relevant and it is very costly to recruit a rather poorly qualified candidate from an underrepresented social group. The candidates are also older, so their potential to improve their skills on the job is rather low. In a similar way, our efficiency argument is less relevant if the firm can easily assess productivity and does not want to invest in training.

The discussion about implications of our research must address peer effects. The learning mechanism in this paper ignores peer effects. Peer effects are a type of network effects and imply the impact of a student on his fellow students. In theoretical models, they are usually captured by the average ability of students in a school. In this case it is typically efficient to have students enrolled into different schools according to their ability. Note that Meier (2004) provides an exception to this rule of thumb. Full competition between schools typically achieves this selection. On the other hand, Hoxby (2000) argues that good students provide support, in particular for bad students, such that competition leads to allocations which are beneficial for the good students but harmful for overall welfare. Econometric problems are a key cause for inconsistencies in the measurement of peer effects, as the self-selection of students into peer groups typically precludes the estimation of counterfactual evidence (Eisenkopf 2010). Furthermore teachers and other factors may shape the peer effects. Hence it is not surprising that Epple et al. (2006) and Ammermüller and Pischke (2006) refer to very heterogeneous empirical evidence for peer effects.

Peer effects would complicate the model without adding further insight into this argument. School productivity reflects peer effects to a certain extent, as school quality increases with the quality of the peer group. The parameters are exogenous in our model and they do not change with changes in the peer group composition. Now suppose that a peer effect depends on the ability of fellow students (as, for example, Epple et al. (2006) argue). In this case selecting too early implies an additional cost as the peer effect in the high ability school is too low. This cost is not compensated by an increased peer effect in the low ability school. Anyway, the objective of this paper is to examine the lock-in effects generated by early selection. Given the empirical problems associated with the identification of peer effects, we find this focus more appealing with respect to its empirical observability.

\section{Conclusion}

The paper has discussed different selection policies in the context of a parsimonious learning mechanism. We show that incorrect self-perceptions or attitude combined with imperfect performance measurement can cause significant welfare losses in selective edu- 
cational systems, in particular if selection starts too early. Of course, these welfare losses can be mitigated by an investment in better assessment. However, this investment is costly and may be substituted by relatively clean information on attitude. In particular, an affirmative action policy may serve the same purpose as such an investment.

Affirmative action allows for an earlier selection because it helps to identify actual ability which is only imperfectly measured by actual performance in schools. As affirmative action is particularly controversial in higher education, our results do not completely confirm any of the conflicting sides. Proponents may argue with us that positive discrimination will allow more unidentified intelligence into universities. Critiques may respond that higher education is a rather late event in an educational career where attitude and ability have high correlation.

Our results suggest that affirmative action and other policies of positive discrimination should focus on younger children, preferably in kindergarten or primary education. Here it could promote efficiency, redistribution and equality of opportunity at the same time. We extend our argument to recruitment policies. It is sensible to have more relaxed recruiting standards for applicants with a disadvantageous background if this background typically implies a lower ability assessment. Again, positive discrimination is more sensible for junior employees than for senior ones. However, the argument for such a diversity management in companies is less strong than in schools because the applicants are older, and the gaps between attitude and ability are smaller.

The model does not include any optimization problem for the students. Hence, incentive problems or strategic considerations do not arise. This omission is very much in line with similar theoretical contributions such as Compte and Postlewaite (2004) where selfperception and actual ability differ. It requires future research to address the problem if confidence is actually a choice variable. It goes beyond the scope of this paper to investigate the non-trivial subsequent strategic interactions.

For our purpose it is sufficient to have a learning process in which the correlation between ability and attitude increases over time. Of course the persistent difference between the two factors is a severe deviation from standard economic theory. However, it is evident among adolescents (see, for example, Köller 2004), and, as we have shown, relevant for economic policy.

Acknowledgements: Gerald Eisenkopf gratefully acknowledges financial support by Deutsche Forschungsgemeinschaft (DFG) through the research group Heterogeneous Labor: Positive and Normative Aspects of the Skill Structure of Labor. The authors thank seminar participants in Konstanz and at the Personalökonomisches Kolloquium in Bonn for stimulating intellectual support. The usual disclaimer applies.

\section{Endnotes}

1 Another strand in the literature investigates self-selection effects of educational institutions and typically identifies a selection outcome based on ability as an efficient solution (e.g., Epple et al. 2003).

2 We do not specifically explore physiological development (e.g., puberty) which likely affects attitude as well (Pekkarinen 2008). 
3 Note that there are various psychological concepts which refer to self-perception, such as selfefficacy (Bandura 1982) or locus of control (Rotter 1966). Recent econometric contributions support the relevance of these concepts (e.g., Heckman and Rubinstein 2001; Heckman et al. 2006).

4 There is some evidence that non-verifiable psychological states correlate with observable variables. Croson and Gneezy (2009) provide a survey about gender differences in risk-attitudes and decision making.

5 Making ability gains in period 1 dependent on ability does not change results qualitatively but requires more description throughout the model.

6 Of course, if $\mathrm{a}_{1}<0$, the learning process in period 2 implies decreasing ability. For those students, education optimally ends after period 1 . The problem could be circumvented by assuming a truncated normal distribution of ability (truncated at zero). Doing so would not lead to additional insights while the exposition becomes less tractable.

7 Student performance after a time $\tau$ in period 1 exactly amounts to $\pi=\alpha+\alpha A+\tau \mathrm{S}_{1}$. Statistical inference concerning ability and attitude is not affected by the deterministic term $\tau \mathrm{S}_{1}$ and is therefore omitted throughout the model exposition.

8 See, e.g. DeGroot and Schervish 2002, p. 313 f.

9 It combines standard updating of a normally distributed variable with a sample from a normal distribution (see, e.g., DeGroot and Schervish 2002, p. $338 \mathrm{ff}$ ), and the continuity correction in $f(\pi)=\frac{1}{1+\alpha} \mathrm{f}\left(\frac{\pi}{1+\alpha}\right)$ for a function of a random variable (see Fisz 1970, p. 58).

10 For a derivation and application of using a normal sample that aggregates two random variables - each having a distinct normal distribution - to make separate inferences about each of the two variables, see Jeon (1996).

11 This is apparent from $\frac{\partial}{\partial \alpha} \bar{t}=\frac{i}{\alpha}\left(\frac{\bar{q}_{\mathrm{t}}(1-\alpha)}{\alpha}\right)=\frac{1-\bar{q}_{\mathrm{t}}}{\alpha^{2}}>0$.

12 In essence, our assumption of selection quality to be in this form qualitatively mirrors the features that the development of exact likelihoods for correct selection based on the underlying normal distributions of attitude and ability would have.

13 Of course, a policy maker may also appreciate a high overall attitude. In this case observed performance would provide better information and allows for better selection decisions.

14 See appendix for derivation.

15 We abstract from the issue of optimizing students who select school types. See Chen and Sönmez (2006) for an analysis of school choice.

16 We thank an anonymous reviewer for suggesting the following example to discuss problems with affirmative action.

\section{Appendix}

Derivation of total surplus (9):

The total surplus obtains as

$$
T S(t)=t c+(1-t) \times\left\{\begin{array}{l}
p[\gamma(h+t c)+\beta(l+t c)] \\
+(1-p) q_{t}[\gamma(h+t c)+\beta(l+t c)] \\
+(1-p)\left(1-q_{t}\right)[\beta(h+t c)+\gamma(l+t c)]
\end{array}\right\}
$$


where $t c$ is the surplus from comprehensive schooling for a period $t$ for the entire population and $(1-t) \times\{0\}$ represents selection gains (or losses). Term $p[\gamma(h+t c)+\beta(l+t c)]$ denotes ability gains of those who are by assumption correctly selected into schools, i.e. those students where ability and attitude match; term $(1-p) q_{t}[\gamma(h+t c)+\beta(l+t c)]$ in line two presents ability gains of correctly selected students where ability and attitude do not match, and term $(1-p)\left(1-q_{t}\right)[\beta(h+t c)+\gamma(l+t c)]$ those gains where selection is incorrect, i.e. high (low) ability students selected into school $\beta(\gamma)$. Rearranging (10) yields

$$
T S(t)=t c+(1-t) \times\left\{\begin{array}{l}
p \cdot[(\gamma h+\beta l)+t c(\gamma+\beta)] \\
+(1-p) q_{t} \cdot[(\gamma h+\beta l)+t c(\gamma+\beta)] \\
+(1-p)\left(1-q_{t}\right) \cdot[(\beta h+\gamma l)+t c(\gamma+\beta)]
\end{array}\right\}
$$

or, equivalently

$$
\begin{aligned}
T S(t)=t c+(1-t) \times\left\{\begin{array}{l}
t c(\gamma+\beta) \cdot\left[p+(1-p) q_{t}(1-p)\left(1-q_{t}\right)\right]+p \cdot[(\gamma h+\beta l)] \\
+(1-p) q_{t} \cdot[(\gamma h+\beta l)] \\
+(1-p)\left(1-q_{t}\right) \cdot[(\beta h+\gamma l)]
\end{array}\right. \\
=t c+(1-t) \times\left\{\begin{array}{l}
t c(\gamma+\beta)+p \cdot[(\gamma h+\beta l)] \\
+(1-p) q_{t} \cdot[(\gamma h+\beta l)] \\
+(1-p)\left(1-q_{t}\right) \cdot[(\beta h+\gamma l)]
\end{array}\right\}
\end{aligned}
$$

where (11) is identical to (9)

Proof of proposition 1

(a) Derivation of (9) with respect to $t$ yields an equation which is linear in $t$. Proper factorization leads to

$$
t^{*}=\frac{\kappa_{1}+\alpha \kappa_{2}}{\kappa_{3}+\alpha \kappa_{2}}
$$

Where

$$
\begin{aligned}
& \kappa_{1}=c+c(\gamma+\beta)-(\gamma h+\beta l) \\
& \kappa_{2}=2(1-p)(\gamma-\beta)(h-l) \\
& \kappa_{3}=2 c(\gamma+\beta)
\end{aligned}
$$

The limit obtains as

$$
\lim _{\gamma \rightarrow \infty} t^{*}=\frac{1}{2} \frac{c-h+2 \alpha(1-p)(h-l)}{c+\alpha(1-p)(h-l)}
$$

Here, $c>h$ is a sufficient condition for $t^{*}>0$. 
The derivative of $t^{*}$ with respect to $\alpha$ obtains as

$$
\frac{\partial t^{*}}{\partial \alpha}=\frac{\kappa_{2}\left(\kappa_{3}-\kappa_{1}\right)}{\left(\kappa_{3}-\alpha \kappa_{2}\right)^{2}}>0
$$

where the inequality follows from $\kappa_{2}>0$ and $\left(\kappa_{3}-\kappa_{1}\right)>0$.

To determine the derivative of $t^{*}$ with respect to $p$ rearrange (13) such that

$$
t_{\text {rearr }} *=\frac{\kappa_{1}+(1-p) \kappa_{4}}{\kappa_{3}+(1-p) \kappa_{4}}
$$

where

$$
k_{4}=2 \alpha(\gamma-\beta)(h-1)
$$

Then the derivative of $t_{\text {rearr }}{ }^{*}$ with respect to $p$ obtains as

$$
\frac{\partial t_{\text {rearr }} *}{\partial p}=\frac{\kappa_{4}\left(\kappa_{3}-\kappa_{1}\right)}{\left(p \kappa_{4}-\kappa_{3}-\kappa_{4}\right)^{2}}<0 .
$$

After proper factorization, the other derivatives obtain as

$$
\begin{aligned}
& \text { (b) } \frac{\partial t^{*}}{\partial c}=-\frac{2 \alpha(1-p)(\gamma-\beta)(h-l)(\gamma+\beta-1)-2(\gamma+\beta)(\gamma h+\beta l)}{\left(\kappa_{3}+\alpha \kappa_{2}\right)^{2}} \\
& \text { (c) } \frac{\partial t^{*}}{\partial \gamma}=\frac{-2 c[\beta(h-l)+c]+2 \alpha(1-p)(h-l)[\beta(h+l+2 c)-c]}{\left(\kappa_{3}+\alpha \kappa_{2}\right)^{2}} \\
& \text { (d) } \frac{\partial t^{*}}{\partial \beta}=-\frac{-2 c[\gamma(h-l)-c]+2 \alpha(1-p)(h-l)[\gamma(h+l+2 c)-c]}{\left(\kappa_{3}+\alpha \kappa_{2}\right)^{2}}
\end{aligned}
$$

Proof of proposition 2

In technical terms the problem can be defined at $t=0$ as follows.

$$
\begin{aligned}
\max _{w} \operatorname{corr}(a,(a+\alpha A+w X) \\
=\frac{E((a-\mu)(a+\alpha A+w X-\mu(1+\alpha+w)))}{\sigma \times \sqrt{\operatorname{Var}(a)+\alpha^{2} \operatorname{Var}(A)+w^{2} \operatorname{Var}(X)+2 \alpha \operatorname{Cov}(a, A)+2 \alpha w \operatorname{Cov}(A, X)}} \\
=\frac{E((a-\mu)(a+(1-\alpha) A+w X-\mu(1+(1-\alpha)+w)))}{\sigma^{2} \times \sqrt{\left(1+\alpha^{2}+w^{2}+2 \alpha p+2 \alpha w \theta\right)}}
\end{aligned}
$$

The relevant first order condition is therefore

$$
\begin{aligned}
& \frac{E((a-\mu)(X-\mu))}{\sigma^{2} \times \sqrt{\left(1+\alpha^{2}+w^{2}+2 \alpha p+2 \alpha w \theta\right)}} \\
& -\frac{E((a-\mu)(a+\alpha A+w X-\mu(1+\alpha+w))) \cdot(w+\alpha \theta)}{\sigma^{2} \times\left(1+\alpha^{2}+w^{2}+2 \alpha p+2 \alpha w \theta\right)^{3 / 2}}=0
\end{aligned}
$$


The first expression is zero, as $X$ correlates only with $A$ but not with $a$. Hence either of the following conditions has to hold:

$$
\begin{gathered}
E((a-\mu)(a+(1-\alpha) A+w X-\mu(1+(1-\alpha)+w)))=0, \quad \text { or } \\
w=-\alpha \theta
\end{gathered}
$$

(17) cannot hold given positive correlation between $a$ and observed performance. Therefore (18) must hold implying $w^{*}<0$.

\section{References}

Achtziger A, Gollwitzer PM (2006) Motivation und Volition im Handlungsverlauf. In: Heckhausen $\mathrm{H}$, Heckhausen J (eds) Motivation und Handeln. Springer, Heidelberg, pp 277-302

Ammermüller A, Pischke J-S (2006) Peer effects in European primary schools: evidence from PIRLS. ZEW Discussion Paper, Mannheim

Arnott R, Rowse J (1987) Peer group effects and educational attainment. J Public Econ 32:287-305

Arrow KJ (1973) The theory of discrimination. In: Ashenfelter O, Rees A (eds) Discrimination in labor markets. Princeton University Press: Princeton, NJ

Bandura, A. (1982) Self-efficacy mechanisms in human agency. Am Psychol 37:227-247

Bauer P, Riphahn RT (2006) Timing of school tracking as a determinant of intergenerational transmission of education. Econ Lett 91(1):90-97

Blanden J, Gregg P, Macmillan L (2007) Accounting for intergenerational income persistence: noncognitive skills, ability and education. Econ J 117(519):C43-C60

Brunello G, Checchi D (2007) Does school tracking affect equality of opportunity? New international evidence. Econ Policy 22(52):781-861

Brunello G, Giannini M, Ariga K (2004) The optimal timing of school tracking. IZA Discussion Paper No. 995. Available at SSRN: http://ssrn.com/abstract=500882

Chen Y, Sönmez T (2006) School choice: an experimental study. J Econ Theory 127:202-231

Compte O, Postlewaite A (2004) Confidence-enhanced performance. Am Econ Rev 94(5):15361557

Croson R, Gneezy U (2009) Gender differences in preferences. J Econ Lit 47(2):448-474

De Fraja G, Landeras P (2006) Could do better: the effectiveness of incentives and competition in schools. J Pub Econ 90:189-213

DeGroot MH, Schervish MJ (2002) Probability and statistics, 3rd ed. Boston: Addison Wesley

Dustmann C (2004) Parental background, secondary school track choice, and wages. Oxf Econ Pap $56: 209-230$

Eisenkopf G (2009) Student selection and incentives. Z Betriebswirtsch 79(5):563-577

Eisenkopf G (2010) Learning, motivation and peer effects. Econ Educ Rev 29:364-374

Epple D, Romano R, Sieg H (2006) Admission, tuition, and financial aid policies in the market for higher education. Econom 74:885-928

Epple D, Romano RE, Sieg H (2003) Peer effects, financial aid, and selection of students into colleges and universities: An empirical analysis. J App Econom 18(5):501-525

Fabel O (2005) Spinoffs of entrepreneurial firms: an o-ring approach. J Inst Theor Econ 160(3):416438

Fisz M (1970) Wahrscheinlichkeitsrechnung und mathematische Statistik, 5 ed. In: Grell H, Maruhn K, Rinow W (eds) Hochschulbücher für Mathematik, Vol. 40. Berlin: VEB Deutscher Verlag der Wissenschaften

Forsyth A, Furlong A (2003) Access to higher education and disadvantaged young people. Br Educ Res J 29:205-225 
Fu Q (2006) A theory of affirmative action in college admission. Econ Inq 44(3):420-428

Furstenberg EK (2007) The informational value of affirmative action in college admissions. B E J Econom Anal 7(1):1-11, Article 36

Gilbert JA, Stead BA, Ivancevich JM (1999) Diversity management: a new organizational paradigm. J Bus Ethics 21(1):61-76

Hanushek EA, Woessmann L (2006) Does educational tracking affect performance and inequality? Differences-in-differences evidence across countries. Econ J 116:C63-C76

Hattie J, Timperley H (2007) The power of feedback. Rev Edu Res 77(1):81-112

Heckhausen H, Gollwitzer PM (1987) Thought contents and cognitive functioning in motivational versus volitional states of mind. Motiv Emot 11:101-120

Heckman J, Rubinstein Y (2001) The importance of noncognitive skills: lessons from the GED testing program. Am Econ Rev 91:145-149

Heckman J, Stixrud J, Urzua S (2006) The effects of noncognitive abilities on labor market outcomes and social behaviour. J Labor Econ 24(3):411-482

Holzer HJ, Neumark D (2000) Assessing affirmative action. J Econ Lit 38:483-568

Hoxby CM (2000) Does competition among public schools benefit students and taxpayers? Am Econ Rev 90(5):1209-1238

Jeon S (1996) Moral hazard and reputational concerns in teams: implications for organizational choice. Int J Indus Organ 14:297-315

Judson R (1998) Economic growth and investment in education: how allocation matters. J Econ Growth 3(4):337-359

Köller O (2004) Konsequenzen von Leistungsgruppierungen. Waxmann, Münster

Kochan T, Bezrukova K, Ely R, Jackson S, Joshi A, Jehn K, Leonard J, Levine D, Thomas D (2003) The effects of diversity on business performance: report of the diversity research network. Hum Resour Manage 42(1):3-21

Lazear E (2001) Educational production. Q J Econ 116(3):777-803

Lee VE, Burkam DT (2002) Inequality at the starting gate: social background differences in achievement as children begin school. Economic Policy Institute, Washington, DC

Lundberg SL, Startz R (1983) Private discrimination and social intervention in competitive labor market. Am Econ Rev 73(3):340-347

Manning A, Pischke J-S (2006) Comprehensive versus selective schooling in england and wales: what do we know? Centre for the economics of education. London School of Economics, London

Meghir C, Palme M (2005) Educational reform, ability, and family background. Am Econ Rev 95:414-424

Meier V (2004) Choosing between school systems: The risk of failure. Finanzarchiv 60(1):83-93

Milgrom P, Roberts J (1992) Economics, organization and management. Prentice Hall, Englewood Cliffs

Pekkarinen T (2008) Gender differences in educational attainment: evidence on the role of the tracking age from a finnish quasi-experiment. Scand J Econ 110(4):807-825

Phelps ES (1972) The statistical theory of racism and sexism. Am Econ Rev 62(4):659-661

Rotter J (1966) Generalized expectancies for internal versus external control of reinforcement. Psychol Monogr 80:1-28

Schuetz G, Ursprung H, Woessmann L (2008) Education policy and equality of opportunity. Kyklos 61(2)279-308

Sternberg RJ, Williams WM (2002) Educational psychology. Allyn and Bacon, Boston

Sutton Trust (2008) Increasing higher education participation amongst disadvantaged young people and schools in poor communities. Report to the National Council for Educational Excellence

Von Bergen CW, Soper B, Foster T (2002) Unintended negative effects on diversity management. Public personnel management 31(2):239-252 
Waldinger F (2007) Does ability tracking exacerbate the role of family background for students' test scores? London School of Economics, London

Wild E, Hofer M, Pekrun R (2001) Psychologie des Lerners. In: Krapp A, Weidenmann B (eds) Pädagogische Psychologie. Beltz, Weinheim: Beltz, pp 207-270

Wright P, Ferris SP, Hiller JS, Kroll M (1995) Competitiveness through management of diversity: effects on stock price valuation. Acad Manage J 38:272-287 